\title{
Anxiety And Depression :Their Epidemiological Factors----A Study on The Patients Attending Psychiatric OPD of a Teaching Hospital, Kolkata, West Bengal
}

\author{
${ }^{1}$ Dr. Sarmila Mallik, ${ }^{2}$ Dr Abhik Sinha, ${ }^{3}$ Dr Prasanta Kumar Das, ${ }^{4}$ Dr.Sanchari \\ Roy, ${ }^{5}$ Dr Kanti Bhushan Choudhury, ${ }^{6}$ Dr. Asish Mukhopadhyay \\ ${ }^{I}$ Associate Professor, Dept of Community Medicine Calcutta National Medical College, Kolkata \\ ${ }^{2}$ Assistant Professor, Dept of Community Medicine, R.G Kar Medical College, Kolkata \\ ${ }^{3}$ Associate Professor, Dept of Psychiatry Calcutta National Medical College, Kolkata \\ ${ }^{4}$ RMO cum Clinical Tutor, Dept of Psychiatry R.G Kar Medical College, Kolkata \\ ${ }^{5}$ Assistant Professor, Dept of Community Medicine Calcutta National Medical College, Kolkata \\ ${ }^{6}$ Professor and Head, Dept. of Psychiatry Calcutta National Medical College, Kolkata
}

\begin{abstract}
:
Background: A sound mind in a sound body has been recognized as a social idea for many centuries. Out of different types of mental health problems depression and anxiety disorders are most common.

Aims and objectives: To assess the socio-demographic and clinical profile of depression and anxiety disorder patients attending psychiatry OPD of Calcutta National Medical College.

Methodology: An observational, descriptive study was carried out on the patients attending psychiatry OPD of Calcutta National Medical College from May 2012 to July 2012, suffering from depression and anxiety disorders. Data were collected by interviewing all the patients using a predesigned, pretested schedule after getting informed consent from them, excluding those who were unwilling.

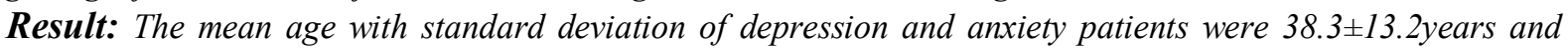
$34.7 \pm 18.2 y e a r s$ respectively. Majority of the study subjects were either illiterate or just literate, belonging to socioeconomic class IV, V or VI, engaged in occupation like unskilled worker, businessman or housewife. Among depression patients females were more than male where as in anxiety disorders males were more than female. In majority of the patients, onset was insidious and duration of illness was less than 5 years, with one third of patients having positive family history. Somatic symptoms were present in a large number of patients.
\end{abstract}

Key words: Depression, Anxiety disorders, Socio-demographic profile.

\section{Introduction:}

A sound mind in a sound body has been recognized as a social idea for many centuries. WHO defined mental health as "Mental health is a state of well being in which the individual realizes his or her own abilities, can cope with the normal stresses of life ; can worth productivity and fruitfully, and is able to make contribution to his or her community." There are different types of mental health problems, some of which are common, such as depression and anxiety disorders and some not so common, such as schizophrenia and bipolar disorders ${ }^{2}$. Prevalence of depression in India is 7.9 to 8.9 per 1000 population and almost twice in urban population ${ }^{3}$. Prevalence of different anxiety disorders-Generalized Anxiety Disorder, Phobia, Obsession, Hysteria varies from 4-6\% in India ${ }^{4}$.Different socio-pathological conditions like emotional stress, unhappy marriage, broken homes, rapid urbanization, economic insecurity play important role in causation of depression and anxiety disorders. ${ }^{5}$ With this perspective the present study was performed with the objectives -to assess the socio-demographic and clinical profile of depression and anxiety disorder patients attending psychiatry OPD of Calcutta National Medical Colleg.

\section{Methodology:}

This observational descriptive study was carried out at Psychiatric OPD of Calcutta National Medical College from May 2012 to July 2012. All the patients suffering from depression, or anxiety disorders as diagnosed by the Psychiatrists in the OPD who came to the OPD during first two months of our study period were interviewed using a pre-designed, pretested schedule after getting informed consent from them. Ethical clearance was taken from Calcutta National Medical College .

Information was collected regarding socio-demographic profile like age, sex ,educational status etc. and about clinical profile like mode of onset, duration of illness etc. Data collection was done every day during 
OPD hours (9am to 2pm) except Sunday. Total 480 patients were interviewed, avoiding repetition carefully and excluding those who did not gave informed consent and this constitutes our study population .

\section{Results:}

Out of total study population, $82.5 \%$ were suffering from depression and $17.5 \%$ from anxiety disorders. Table 1 shows that more than half of the patients suffering from depression $(50.3 \%)$ and anxiety $(55.9 \%)$, were in the age group of $20-40$ years, less than $10 \%$ of them were below 20 years and $3-4 \%$ were in the age group of 60 years and above. The mean age with standard deviation of depression and anxiety patients were $38.3 \pm 13.2$ yearsand $34.7 \pm 18.2$ years respectively, the difference between the means were not statistically significant. Among depression patients, proportion of females(67.9\%)were more than males, where as in anxiety disorders proportion of males $(53.6 \%)$ were more than that of females $(46.4 \%)$, the difference between the proportions were statistically significant. Most of the depression (67.9\%) and anxiety disorder(70.2\%)patients were illiterate and just literate, the difference of proportion was not statistically significant. Regarding occupation, in depression and anxiety patients unskilled worker $(26.8 \%$ and $25.0 \%$ respectively)and businessmen( $26.8 \%$ and $25.0 \%$ respectively) were most common . According to modified B.G Prasad Scale, most of the patients suffering from depression, and anxiety (32.3\%and 28.5\%,respectively) belonged to SE status IV, followed by status V and VI(26.1\%and26.2\% in case of depression and anxiety respectively), without any significant difference of proportion between these two categories of patients. Around half of the patients of both anxiety and depression had addiction (approx.48.8\%and 53.5\% respectively), the difference of proportion was statistically not significant. Among depression patients $43.7 \%$ were addicted to tobacco, $8.8 \%$ to alcohol and $1.0 \%$ to both alcohol and tobacco, in anxiety patients these percentages were $25.0 \%, 17.9 \%$ and $5.9 \%$ respectively. $70.5 \%$ of depression patients and $84.5 \%$ anxiety patients were married, the difference of proportion was statistically significant. Regarding religion, there was no significant difference of proportion among depression and anxiety patients, $46.7 \%$ and $54.8 \%$ of them were Hindus respectively. $59.35 \%$ depression patients and $45.2 \%$ anxiety patients came from nuclear family(the difference was statistically significant) and rest from joint family. Table 2 shows that majority of the patients, suffering from depression ,and anxiety (68.9\%and,63.1\%, respectively ) had insidious onset. Duration of illness was less than 5 years in $67.7 \%$ and $61.9 \%$, patients suffering from depression and anxiety respectively, whereas the duration was more than 10 years in $14.4 \%$ depression patients and $23.8 \%$ anxiety patients and in rest of the cases duration of illness was 5-10 years. In about one third of the patients $(33.6 \%$ in depression $\& 29.8 \%$ in anxiety disorders) mental illness was present among family members .No statistically significant difference of proportion was found between depression \&anxiety patients regarding onset, duration and family history. In depression patients most common presenting complain was low mood (72.9\%), followed by headache $(60.1 \%)$,and less sleep $(55.1 \%)$. Most common symptom in anxiety patients was irritability (80.9\%),followed by less sleep(72.6\%) and headache(59.5\%).

\section{Discussion:}

In this study, majority of the study subjects were in the age group of 20-40 years, either illiterate or just literate, belonging to socioeconomic class IV,V or VI, engaged in occupation like unskilled worker, businessman or housewife. Among depression patients females were more than male where as in anxiety disorders males were more than female Around half of the patients had addiction, tobacco being the most common form of addiction. Majority of the study subjects were married and the proportion of Hindu and Muslim patients were almost equal. $29.5 \%$ of depression patients and $15.5 \%$ anxiety disorder patients were single. Majority of patients suffering from depression came from nuclear family where as majority of anxiety patients came from joint family. There was no significant difference between depression and anxiety patients regarding mean age, educational status, socioeconomic status, religion and addiction, where as difference between these two groups of patients was significant regarding gender, marital status and type of family. Different studies found that depression was more common in women ${ }^{6,7,8,9}$, in younger subjects, ${ }^{10}$ in those coming from poor economic background, ${ }^{11,12}$ in Muslims $^{8}$, in those residing in nuclear family ${ }^{13}$ and were divorced or widowed. ${ }^{7}$ It was reported from different studies that anxiety disorders were 2 to 3 times more common in females compared to males. ${ }^{14,15,16}$ Saygili $\mathrm{S}$ et al found that $9.1 \%$ of anxiety patients were divorced or widowed and majority of them $(58.4 \%)$ were married. ${ }^{14}$ Table 2 shows that majority of the patients, suffering from depression and anxiety had insidious onset with duration of illness was less than 5 years. In about one third of the patients (approx. 30-34\%) , mental illness was present among family members. No statistically significant difference of proportion was found between depression \& anxiety patients regarding onset, duration and family history. In depression patients most common presenting complain was low mood (72.9\%), followed by headache $(60.1 \%)$,and less sleep $(55.1 \%)$ whereas most common symptom in anxiety patients was irritability(80.9\%),followed by less sleep(72.6\%) and headache(59.5\%).Most of the researchers reported high 
prevalence of somatic symptoms in depression and some studies report that somatic symptoms are the most common manifestation of depression in India. . $^{17,18,19,20}$

\section{Conclusion}

No significant difference was found between anxiety and depression patients regarding distribution of age, educational and socio-economic status, religion, and addiction, where as the difference was significant in sex distribution, marital status and type of family. Most common symptom was low mood in depression patients and irritability in patients suffering from anxiety disorders.

\section{References:}

[1]. Mental Health: Strengthening Our Response. World Health Organization.

[2]. Kitchener BA \& Jorm AF.2002.Mental Health First aid Manual. Centre for Mental Health Research. Canberra.p5

[3]. Reddy MV, Chandrasekhar CR. Prevalence of mental and behavioural disorders in India: a meta analysis. Indian J Psychiatry1998.40:149-57.

[4]. Trivedi J.K, Gupta P.K. An Overview of Indian Research in Anxiety Disorders. Indian J. Psychiatry.2010. January.52(Suppl1):S210-S218.

[5]. K Park. Park's Textbook of Preventive and Social Medicine.2009.p736

[6]. Sethi BB, Prakash R. Depression in Industrial population. Indian J Psychiatry. 1979; 21:359-61.

[7]. Sai S, Pradeepa R, Ganesan A, Mohan V. Prevalence of depression in a large urban South Indian Population—The Chennai Urban Rural Epidemiology. 2009;4: $\mathrm{E}_{7} 185$.

[8]. Banerjee G, Boral GC, Ganguli H, Ajmany S, Ghosh A, Sarkar S. Socio-economic status and prevalence of mental disorders in certain rural areas in India. Acta Psych Scand. 1979; 59:276-93.

[9]. Ramachandran V, Menon MS, Arunagiri S. Socio-cultural factors in late onset depression. Indian J. psychiatry. 1982; 24: 268-73

[10]. Ponnudurai R, Somasundaram O, Balakrishnan S, Srinivasan N. Depression-a study of 80 cases. Indian J. Psychiatry. 1981; 23: 256-8.

[11]. Bagadia VN, JesteDV, Doshi SU, Shah LP. Depression: A clinical study of 233 cases. Indian J Psychiatry. 1973; 15: 224-30.

[12]. Mohandas E. Road map to Indian Psychiatry. Indian J Psychiatry.2009; 51:173-9.

[13]. Sethi BB, Sharma M. Depressive disorders and family constellation. Indian J Psychiatry. 1980; 22: 69-73.

[14]. Saygili S, Karamustafalioglu O. Socio-demographic characteristics and comorbidity in panic disorder patients. The J of Psychiatry and Neurological sciences. 2010; 23:32-37.

[15]. Breier A, Charney DS, Hennger GR. Major depression in patients with agarophobia and panic disorder. Arch Gen psychiatry. 1984; 41:1129-1135.

[16]. Gorman JM. Anxiety disorders: Introduction and overview; In Sadock B, Sadock V(editors). Kaplan and Sadock's Comprehensive Textbook of Psychiatry. Seventh Ed. Philadelphia. Lippincott Williams and Wilkins, 2000,1441.

[17]. Shah S, Derasari VD. Comparison of symptomatology of depression between India and U.S.A. Indian J Psychiatry. 1988; 30:12934.

[18]. Teja S, Narang RL, Aggarwal AK. Depression across cultures. British J Psychiatry.1971;119:253-60.

[19]. Singh G, Verma HC. Depressive equivalents pain as a symptom of depression. Indian J Psychiatry.1971; 13:49-55.

[20]. Chaturvedi SK, Sarmukaddam S. Negative symptoms in depression. Indian j Psychiatry.1985;27:139-44.

Table1: Distribution of study population according to socio-demographic profile $(\mathbf{N}=480)$

\begin{tabular}{|l|l|l|l|}
\hline Socio-demographic profile & $\begin{array}{l}\text { Depression } \\
\text { (Total no.=396) }\end{array}$ & $\begin{array}{l}\text { Anxiety } \\
\text { ( Total no.=84) }\end{array}$ & Test of significance \\
\hline Age groups in years & & & \\
\hline$<20$ & $24(6.1 \%)$ & $8(9.5 \%)$ & \\
\hline $20-40$ & $199(50.3 \%)$ & $47(55.9 \%)$ & \\
\hline $40-60$ & $157(39.6 \%)$ & $28(30.9 \%)$ & \\
\hline$>=60$ & $16(4.0 \%)$ & $3(3.7 \%)$ & $\mathrm{t}=1.72, \mathrm{p}>0.05$ \\
\hline Mean \&SD & $38.3 \pm 13.2$ & $34.7 \pm 18.2$ & \\
\hline Gender & & & $\mathrm{Z}=3.64, \mathrm{p}<0.05$ \\
\hline Male & $127(32.1 \%)$ & $45(53.6 \%)$ & \\
\hline Female & $269(67.9 \%)$ & $39(46.4 \%)$ & $\mathrm{Z}=0.42, \mathrm{p}>0.05$ \\
\hline Educational status & & & \\
\hline Illiterate & $167(42.2 \%)$ & $38(45.2 \%)$ & \\
\hline just literate & $102(25.8 \%)$ & $21(25.0 \%)$ & \\
\hline Primary & $87(22.0 \%)$ & $13(15.5 \%)$ & \\
\hline Secondary & $32(8.0 \%)$ & $1(11.9 \%)$ & \\
\hline H.S \& above & $8(2.0 \%)$ & $2(2.4 \%)$ & \\
\hline Occupation & & & \\
\hline Service & $63(15.9 \%)$ & $17(20.2 \%)$ & \\
\hline Business & $106(26.8 \%)$ & $21(25.0 \%)$ & \\
\hline Unemployed & $58(14.6 \%)$ & $8(9.5 \%)$ & \\
\hline Unskilled worker & $106(26.8 \%)$ & $21(25.0 \%)$ & \\
\hline Housewife & $51(12.9 \%)$ & $13(15.5 \%)$ & \\
\hline Student & $12(3.0 \%)$ & $4(4.8 \%)$ & \\
\hline Socio-economic status & & & \\
\hline I & $44(11.1 \%)$ & $11(13.1 \%)$ & \\
\hline II & $48(12.1 \%)$ & $13(15.5 \%)$ & \\
\hline III & $73(18.4 \%)$ & $14(16.7 \%)$ & \\
\hline IV & $128(32.3 \%)$ & $24(28.5 \%)$ & \\
\hline & & & \\
\hline
\end{tabular}


Anxiety And Depression, Their Epidemiological Factors----A Study On The Patients ....

\begin{tabular}{|l|l|l|l|}
\hline V\&VI & $103(26.1 \%)$ & $22(26.2 \%)$ & \\
\hline Addiction & & & \\
\hline Alcohol & $35(8.8 \%)$ & $15(17.9 \%)$ & \multirow{Z}{Z}{$=0.78, \mathrm{p}>0.05$} \\
\cline { 1 - 3 } Tobacco & $173(43.7 \%)$ & $21(25.0 \%)$ & \\
\hline Both & $4(1.0 \%)$ & $5(5.9 \%)$ & \\
\hline Nil & $184(46.5 \%)$ & $43(51.2 \%)$ & \\
\hline Marital Status & & & $\mathrm{Z}=3.07, \mathrm{p}<0.05$ \\
\hline Married & $279(70.5 \%)$ & $71(84.5 \%)$ & \\
\hline Single & $117(29.5 \%)$ & $13(15.5 \%)$ & \\
\hline Religion & & & $\mathrm{Z}=1.35, \mathrm{p}>0.05$ \\
\hline Hindu & $185(46.7 \%)$ & $46(54.8 \%)$ & \\
\hline Muslim & $211(53.3 \%)$ & $38(45.2 \%)$ & \\
\hline Type of family & & & $\mathrm{Z}=2.37, \mathrm{p}<0.05$ \\
\hline Nuclear & $235(59.3 \%)$ & $38(45.2 \%)$ & \\
\hline Joint & $161(40.7 \%)$ & $46(54.8 \%)$ & \\
\cline { 1 - 2 } & & & \\
\hline
\end{tabular}

Table2: Distribution of study population according to clinical profile $(\mathrm{N}=\mathbf{4 8 0})$

\begin{tabular}{|l|l|l|l|}
\hline Clinical profile & $\begin{array}{l}\text { Depression } \\
\text { (Total no.=396) }\end{array}$ & $\begin{array}{l}\text { Anxiety } \\
\text { ( Total no.=84) }\end{array}$ & Test of significance \\
\hline Onset & & & \\
\hline Acute & $123(31.1 \%)$ & $31(36.9 \%)$ & $\mathrm{Z}=1.01, \mathrm{p}>0.05$ \\
\hline Insidious & $273(68.9 \%)$ & $53(63.1 \%)$ & \\
\hline Duration & & & \\
\hline$<5$ years & $268(67.7 \%)$ & $52(61.9 \%)$ & $\mathrm{Z}=0.89, \mathrm{p}>0.05$ \\
\hline $5-10$ years & $71(17.9 \%)$ & $12(14.3 \%)$ & \\
\hline$>10 y e a r s$ & $57(14.4 \%)$ & $20(23.8 \%)$ & \\
\hline Family history & & & \\
\hline Present & $133(33.6 \%)$ & $25(29.8 \%)$ & $\mathrm{Z}=0.69, \mathrm{P}>0.05$ \\
\hline Absent & $263(66.4 \%)$ & $59(70.2 \%)$ & \\
\hline Presenting complains* & & & \\
\hline Headache & $238(60.1 \%)$ & $50(59.5 \%)$ & \\
\hline Vertigo & $145(36.6 \%)$ & $39(46.4 \%)$ & \\
\hline Anorexia & $19(4.8 \%)$ & $26(30.9 \%)$ & \\
\hline Irritability & $41(10.4 \%)$ & $68(80.9 \%)$ & \\
\hline Low mood & $289(72.9 \%)$ & $19(22.6 \%)$ & \\
\hline Less sleep & $218(55.1 \%)$ & $61(72.6 \%)$ & \\
\hline Phobia & $55(13.9 \%)$ & $42(50.0 \%)$ & \\
\hline $\begin{array}{l}\text { Others(excessive } \\
\text { excessive anger etc.) }\end{array}$ & $27(6.8 \%)$ & $9(10.7 \%)$ & \\
\hline
\end{tabular}

*Responses are multiple 